\title{
An update on antibody drug conjugates
}

\begin{abstract}
Antibody Drug Conjugates (ADCs) are an emerging class of biopharmaceuticals in which a target-specific monoclonal antibody combines with small molecule chemotherapeutic agents. ADCs resemble the "magic bullet" version of Paul Ehrlich. Paul Ehrlich, a German chemist, was the first who envisioned the concept of "magic bullet" in which a highly specific drug would be delivered to the target diseased tissue while leaving the healthy tissues intact. ADCs widen the therapeutic index of the cytotoxic chemotherapy and enhance their potency. FDA approved four ADCs thus far. Some are currently undergoing development (see picture). In this review, we will focus on ADCs approved by the FDA thus far in solid tumors as well as in hematological malignancies. Also, we will discuss the ongoing clinical trials using these novel therapeutics.
\end{abstract}

Volume 6 Issue 2 - 2018

\author{
Pavankumar Tandra,' Jairam Krishnamurthy,' \\ Venkatasunil Bendi, ${ }^{2}$ Avyakta Kallam' \\ 'Division of hematology-oncology, University of Nebraska \\ Medical Center, USA \\ ${ }^{2}$ Clinical observer in academic neurology, University of \\ Nebraska Medical center, USA
}

Correspondence: Pavankumar Tandra, Division of hematologyoncology, University of Nebraska Medical Center, Omaha, NE 68116,USA, Email pav.tandra@unmc.edu

Received: February 05, 2018 | Published: March 14, 2018

\section{Introduction}

Antibody Drug Conjugates (ADCs) are an emerging class of biopharmaceuticals in which a target-specific monoclonal antibody combines with small molecule chemotherapeutic agents. ADCs resemble the "magic bullet" version of Paul Ehrlich. Paul Ehrlich, a German chemist, was the first who envisioned the concept of "magic bullet" in which a highly specific drug would be delivered to the target diseased tissue while leaving the healthy tissues intact. ADCs widen the therapeutic index of the cytotoxic chemotherapy and enhance their potency. FDA approved four ADCs thus far. Some are currently undergoing development (see picture). In this review, we will focus on ADCs approved by the FDA thus far in solid tumors as well as in hematological malignancies. Also, we will discuss the ongoing clinical trials using these novel therapeutics.

\section{Pharmacology}

The Structure of the ADC contains three moieties; a monoclonal antibody moiety and the conjugated cytotoxic drug called "payload." A biodegradable stable linker joins these two moieties and discriminates between a healthy cell and a cancer cell. This linker is either cleavable or non-cleavable. The cytotoxic agents are usually inhibitors of tubulin polymerization such as maytansinoids (maytansine; DMs), dolastatins, auristatin analogues and cryptorchin. The tubulin inhibitors inhibit cell division by binding tubulin and arresting the target cell division in the G2/M stage resulting in apoptosis. The goal of an efficient ADC is to identify a target antigen specific to a cancer cell and kill the cancer cell by releasing cytotoxic drug molecules inside the target cell with no associated systemic toxicity. This mechanism of ADCs is in contrast to monoclonal antibodies which act by antibody -dependent cell-mediated cytotoxicity mechanism. ${ }^{1}$ ADCs in Hematological malignancies: One of the first ADC s approved for oncologic indications was Brentuximab Vedotin (BV) in Hodgkin's lymphoma (HL).

\section{Brentuximab vedotin}

$\mathrm{BV}$ is a CD30 targeted ADC. The anti-CD 30 antibody conjugates to an anti-microtubulin agent, monomethyl auristatin E (MMAE) via a peptide linker. ${ }^{2} \mathrm{CD} 30$ expressing cells internalize $\mathrm{BV}$ upon attachment to the receptor. Once internalized, the peptide linker is cleaved, allowing MMAE to be released and resulting in apoptosis. ${ }^{3} \mathrm{CD} 30$ is expressed in Reed-Sternberg cells, thus making BV a potential agent in HL. A landmark phase I study, by Younes et al. ${ }^{4}$ in 2010 enrolled 45 patients with relapsed/refractory patients with $\mathrm{CD} 30+$ hematological cancers. Among these patients, 42 had relapsed/refractory HL. BV, administered on a three-weekly schedule resulted in an objective response (OR) in 50\%. Among the patients who responded, 25\% of the patients demonstrated completed response (CR). The median duration of response and the median progression-free survival (PFS) were 9.7 months 5.9 months respectively. Promising results led to a pivotal phase II study which led to the approval of BV in relapsed/ refractory HL. ${ }^{5}$ One hundred and two patients with HL who had progressed after autologous stem cell transplantation were enrolled to receive BV. Objective responses were seen in $75 \%$, and CR was noted in 34\%. The duration of response for the patients who attained CR was 20.5 months (5). Forty-seven percent of the patients who achieved a CR remained in remission at a median follow up of 53.3 months, confirming the durability of BV. A follow-up study by Chen et al. showed a five-year OS of $41 \%$ and median overall survival of 40 months. ${ }^{6}$ Following the approval of BV, several studies have been designed to explore the role of BV in different clinical scenarios in addition to the post autologous stem cell transplant setting. Studies have shown BV when given before allogenic SCT to improve outcomes post-transplantation, with two year PFS who received pretransplant $\mathrm{BV}$ of $59.3 \%$ when compared to $26.1 \%$ who did not receive $\mathrm{BV} .^{7}$

BV has successfully been used in combination with cytotoxic chemotherapy with impressive results. A study by La Casce et al. ${ }^{8}$ showed that combining $\mathrm{BV}$ and Bendamustine in patients with relapsed/refractory disease post autologous stem cell transplant led to an ORR of $93 \%$ and CR of $74 \%$. A study by Schroder et al. ${ }^{9}$ had 34 of 45 patients achieving PET negativity with BV and augmented ICE (Ifosphamide, Carboplatin, and Etoposide). BV was shown to have durable responses when used in patients with recurrent disease post allo-SCT, a group that traditionally has dismal outcomes. A retrospective analysis of 25 patients with relapsed disease post- 
allo-SCT, showed an ORR of 50\%, and a PFS of 7.8 months $^{10}$. A randomized phase III study was conducted to evaluate the role of BV as maintenance therapy post autologous stem cell transplant in highrisk patients. ${ }^{11}$ A total of 3329 high-risk patients (defined as a primary refractory disease, recurrence $<12$ months, extra nodal involvement at the time of relapse) were enrolled and randomly assigned to receive consolidation therapy with BV. At a median follow up of 30 months, the PFS was significantly better in the BV group when compared to the placebo group (42.9 months v/s 24.1 months). Based on this study, BV was approved as maintenance therapy in patients with high risk relapsed disease. Recently studies have been conducted using BV in the first line setting in patients with HL. A recent ECHELON III phase 3 study evaluated outcomes in patients who received BV, Adriamycin, Vinblastine, Dacarbazine to patients who were treated with traditional ABVD regimen. ${ }^{12}$ The two years PFS was higher in the BV arm when compared to the ABVD arm (82\% vs. $77 \%)$. As expected, the pulmonary toxicities were fewer in the BV arm as well. Based on this data, BV may be making inroads as first-line therapy for patients with advanced HL.

\section{Gemtuzumab ozagamicin (GO)}

GO consists of a semi-synthetic derivative of calicheamicin, a cytotoxic antibiotic linked to an anti CD33 antibody. CD 33 antigen is present on the cell surface of leukemic myeloblasts and is a potential target in acute myeloid leukemia (AML) ${ }^{13}$ It was the first ADC to be approved by the FDA in 2000. It was approved primarily for patients with older patients with AML (age $>60 \mathrm{yrs}$ ) at first relapsed and who were ineligible for cytotoxic chemotherapy. FDA approved this drug based on three open-label, multicenter trials which evaluated the efficacy and safety of single-agent GO in patients with CD 33+AML at first relapse. One hundred and forty-two patients with a median age of 61 years were enrolled and received GO. Thirty percent of patients obtained remission. Among these patients, $16.2 \%$ achieved a CR. ${ }^{14,15}$ Given this positive study, another study, S0106 which randomized 637 adults up to age 60 years with de novo AML to receive two cycles of Daunorubicin/cytarabine induction with or without GO. ${ }^{16}$ This study showed increased treatment-related mortality, mainly increased transaminases, veno occlusive disease of the liver in the GO arm. There was no improvement noted in the OS either. Following this study, FDA withdrew its indication for GO in 2010.

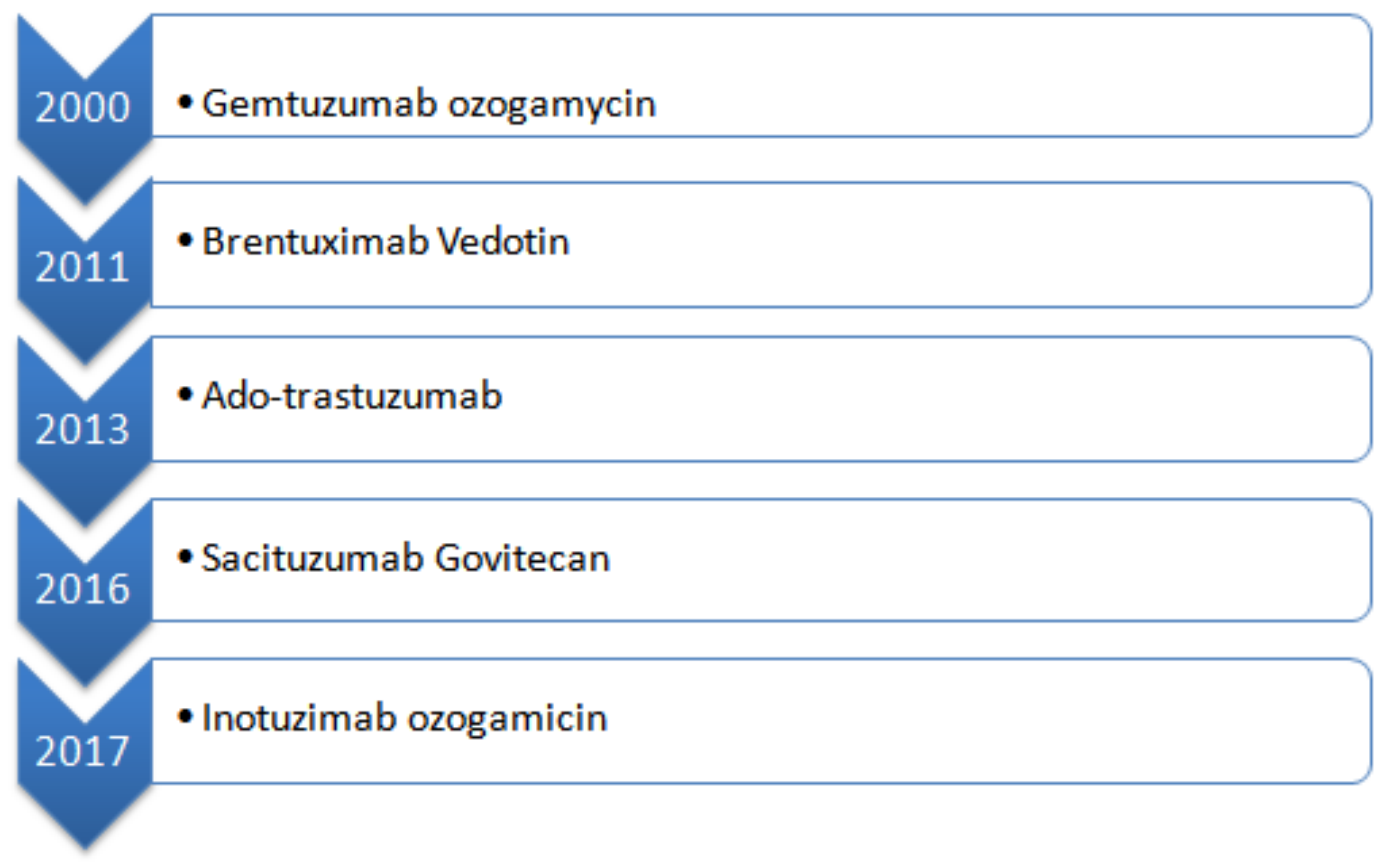

Figure $1 \mathrm{ADC}$ s approved for oncologic indications.

The adverse reactions with GO were thought to be dose-dependent. GO was being administered at a dose of $9 \mathrm{mg} / \mathrm{m} 2$ on days 1 and 14 and this caused significant infusion reactions, myelosuppression and increased transaminases. ${ }^{17}$ Veno-occlusive disease of the liver, in particular, was found to be dependent on the serum concentration of the drug. Also, observed was a lower dose $(3 \mathrm{mg} / \mathrm{m} 2$, administered on days 1,4 and seven) was equally efficacious compared to the higher treatment dose regarding achieving a CR. ${ }^{17}$ Leading to this observation, ALFA-0701, a multicenter, open-labeled, randomized trial of GO $(3 \mathrm{mg} / \mathrm{m} 2$ on days $1,4 \& 7)$ with daunorubicin and cytarabine $\mathrm{v} / \mathrm{s}$ daunorubicin and cytarabine was proposed. ${ }^{18}$ Two hundred and seventy-one patients (ages 50yrs-70yrs) with untreated denovo AML patients enrolled in this study. The three year EFS was significantly higher in the GO arm when compared to the control arm (39.8 vs. 13.6; p-0.001) in this study. A meta-analysis of five studies using GO was conducted and noted that GO reduced the risk of relapse (OR, 0.81; $\mathrm{P}<0.001)$, improved five-year overall survival (OR, 0.90; $\mathrm{p}<0.01) .{ }^{19}$ The survival benefit was most pronounced in patients with favorable and intermediate risk cytogenetics. The lower dose of GO had improved safety. Based on these studies, GO received FDA approval for and has established a new standard of care for patients with newly diagnosed CD 33+ AML (Figure 1).

\section{Inotuzumab ozogamicin (IO)}

IO is a humanized anti-CD 22 antibody conjugated to 
calicheamicin, a cytotoxic antibiotic. Upon binding of the conjugate to $\mathrm{CD} 22$, calicheamicin is released, which binds to the DNA, inducing apoptosis. CD22 receptors are present in more than $90 \%$ of cells with B-cell acute lymphocytic leukemia, thus making this an ideal target for the drug. ${ }^{20}$ A phase III INO-VATE trial an open-labeled, randomized clinical trial designed to assess the clinical activity and safety of IO when compared to standard therapy, in first line and salvage setting in adults with relapsed/refractory B-cell ALL. ${ }^{21}$ Three hundred and twenty-six patients were enrolled. The rate of $\mathrm{CR}$ was higher in the IO group when compared to the standard therapy group $(80.7 \% \mathrm{v} / \mathrm{s}$ $29.4 \%$ ). PFS was significantly higher in the IO group (median of 5.0 months [95\% CI, 3.7 to 5.6] with IO vs. 1.8 months [95\% CI, 1.5 to 2.2] with control; HR, 0.45 [97.5\% CI, 0.34 to 0.61$] ; \mathrm{P}<0.001$ ) and also the median OS. It was 7.7 months ( $95 \%$ CI, 6.0 to 9.2 ) with IO versus 6.7 months $(95 \% \mathrm{CI}, 4.9$ to 8.3$)$ with the standard therapy, and the HR was $0.77(97.5 \% \mathrm{CI}, 0.58$ to 1.03$)(\mathrm{P}=0.04)$. The most frequent grade 3 nonhematologic adverse events with IO were liver-related. Veno-occlusive liver disease of any grade occurred in $11 \%$ of patients who received IO and in $1 \%$ in patients who received standard therapy. Based on this study, IO received FDA approval for patients with B cell ALL in 2017.

\section{Polatuzumab vedotin (PV)}

$\mathrm{PV}$ is an ADC containing an anti-CD79B monoclonal antibody conjugated to the microtubule-disrupting agent MMAE. ${ }^{22}$ CD79 receptors are present on the surface of the B lymphocytes. Preclinical studies have shown good efficacy in patients with B cell NHL. Phase $\mathrm{Ib} / \mathrm{II}$ s study was conducted combining Bendamustine, Rituximab, and PV in patients with refractory Follicular Lymphoma (FL) and Diffuse Large B Cell Lymphoma (DLBCL). ${ }^{23}$ This study was promising with ORR noted in $100 \%$ of patients with FL and $50 \%$ of patients with DLBCL. Moreover, these responses were sustainable, with a median duration of response of 16 months in patients with FL and 13 months in patients with DLBCL. More importantly, long-term follow up in patients with DLBCL revealed an improved in OS of 11 months in the PV arm when compared to the BR (Bendamustine and Rituximab) arm (5.5 months). Based on this data, this drug is expected to receive FDA approval in patients with relapsed/refractory lymphomas. Several studies looking at combination therapy involving PV and CD20 antibodies (Obinituzumab) are ongoing as preclinical data suggested a synergistic activity with these combinations (Table 1).

Table 1 ADCs currently being studied in Hematological malignancies.

\begin{tabular}{|c|c|c|c|c|}
\hline Name & Antibody & Linker & Cytotoxic payload & $\begin{array}{l}\text { Cancers } \\
\text { studied in }\end{array}$ \\
\hline $\begin{array}{l}\text { Vadastuximab } \\
\text { talarine }\end{array}$ & $\begin{array}{l}C D 33 \\
\text { humanized IgG engineered site- } \\
\text { specific antibody }\end{array}$ & $\begin{array}{l}\text { Cleavable } \\
\text { dipeptide }\end{array}$ & $\begin{array}{l}\text { Pyrrolobenzodiazepine } \\
\text { (PBD) } \\
\text { dimer }\end{array}$ & $\begin{array}{l}\text { AML } \\
\text { Phase III }\end{array}$ \\
\hline $\begin{array}{l}\text { Polatuzumab } \\
\text { vedotin }\end{array}$ & $\begin{array}{l}\text { CD79b } \\
\text { humanized } \lg G\end{array}$ & $\begin{array}{l}\text { Cleavable } \\
\text { dipeptide via }\end{array}$ & Auristatin & $\begin{array}{l}\mathrm{NHL} \\
\text { Phase II and Phase III }\end{array}$ \\
\hline $\begin{array}{l}\text { Denintuzumab } \\
\text { mafodotin }\end{array}$ & $\begin{array}{l}\text { CD } 19 \\
\text { humanized IgG }\end{array}$ & Non Cleavable & Maytansinoid & $\begin{array}{l}\text { NHL } \\
\text { Phase II }\end{array}$ \\
\hline $\begin{array}{l}\text { Naratuximab } \\
\text { emtansine }\end{array}$ & $\begin{array}{l}\text { CD } 37 \\
\text { humanized } \lg G\end{array}$ & Non Cleavable & Maytansinoid & $\begin{array}{l}\text { NHL } \\
\text { Phase II }\end{array}$ \\
\hline $\begin{array}{l}\mathrm{C} \circ \mathrm{It} \mathrm{u} \times \mathrm{i} \mathrm{m} \mathrm{a} \mathrm{b} \\
\text { ravtansine }\end{array}$ & $\begin{array}{l}\text { CD } 19 \\
\text { humanized IgG }\end{array}$ & Cleavable disulfide & Maytansinoid & $\begin{array}{l}\mathrm{NHL} \\
\text { Phase II }\end{array}$ \\
\hline
\end{tabular}

Source: Clinicaltrials.gov.

\section{Solid tumors}

\section{Ado-trastuzumab emtansine (also known as T-DMI)}

One of the first ADC, approved in solid tumors was T-DM1 in Her2 positive breast cancer. In T-DM1, the monoclonal antibody moiety of the ADC (Trastuzumab) links the payload DM-1 (a maytansinoid conjugate) via a stable thioether linker, MCC. T-DM1 binds the target antigen on the surface of her- 2 overexpressed cells, internalizes the ADC complex and releases the conjugated chemotherapy drug DM-1 inside the cell, thus minimizing systemic toxicity. DM1, a microtubule inhibitor, kills the target cell by its cytotoxic effects. This strategy helps in overcoming the multidrug resistance in target cells. ${ }^{24}$ Taxane-based chemotherapy was the standard of care for metastatic her 2-positive breast cancer before the approval of Trastuzumab. In combination with taxanes, Trastuzumab is proven to prolong PFS in metastatic Her2 positive breast cancer paving the way for approval by the FDA in $1998 .{ }^{25}$ Given its synergistic activity with taxanes, a microtubule inhibitor, Trastuzumab along with another potent microtubule inhibitor was an appealing model for investigators to develop an ADC. HER2, a transmembrane receptor protein that plays a vital role in cell differentiation, proliferation, and survival, is overexpressed in $20 \%$ of breast tumors. As normal tissues express low levels of Her-2, it was an attractive target to develop an ADC for overexpressed her 2-breast cancer. Also, Her-2 receptor expression is homogeneous among ninety percent of her- 2 positive breast cancers.

After confirming its safety and tolerability in a phase I study of 24 patients, a randomized controlled trial, EMILIA ${ }^{26}$ evaluated T-DM1 with the then standard second-line therapy Capecitabine plus Lapatinib. Among 991 women studies, the median PFS and OS (at second interim analysis) were 9.6 months and 30.9 months with T-DM1 versus 6.4 months and 25.1 months with Lapatinib plus Capecitabine respectively. The hazard ratio for progression from any cause was $0.65(95 \%$ confidence interval [CI] of 0.55 to $0.77 ; \mathrm{P}<0.001)$. The hazard ratio for death from any cause was 0.68 ( $95 \%$ CI of 0.55 to $0.85 ; \mathrm{P}<0.001)$. The benefit of T-DM1 therapy was most pronounced in younger patients with visceral disease. The ORR was also higher with T-DM1 (43.6\%, vs. 30.8\% with Lapatinib plus Capecitabine; $\mathrm{P}<0.001)$. Grade 3 adverse events were $57 \%$ with Lapatinib plus Capecitabine Vs. $41 \%$ with T-DM1. The incidence of thrombocytopenia and increased serum aminotransferase levels were higher with T-DM1, whereas the rates of diarrhea, nausea, vomiting, and palmar-plantar erythrodysesthesia were higher with Lapatinib plus Capecitabine. 
FDA approved T-DM1 in February 2013 as a second line drug for her 2-positive metastatic disease (progression after first-line therapy with Trastuzumab, Pertuzumab, and a Taxane) based on the results of EMILIA study. T-DM1 was the first ADC approved for use in solid tumors. After its approval in second-line setting, another phase III study "MARIANNE,"27 evaluated the efficacy of T-DM1 as a single agent (plus placebo) or in combination with Pertuzumab with Trastuzumab plus a taxane randomizing patients to these three arms in a $1: 1: 1$ ratio. MARIANNE study did not show an increase of PFS in the two T-DM1-containing treatment arms compared to control. Median PFS reported was 15.2 months, 14.1 months and 13.7 months respectively with T-DM1 plus Pertuzumab, T-DM1 alone and Trastuzumab plus a taxane. Also, the ORRs were comparable between the three groups. The authors concluded that the Trastuzumab, Pertuzumab, and a taxane should remain the first-line therapy and T-DM1 became the preferred second-line option. However, given similar OS between the T-DMI and other arms, T-DM1 is a reasonable alternative as a first line treatment for patients who are not candidates for chemotherapy due to poor performance status. Currently, T-DM1, either alone or in combination with chemotherapy or other target agents, is being studied in multiple clinical trials (see Table 2). ${ }^{28}$

Table 2 T-DM1 is being studied in multiple clinical trials.

\begin{tabular}{|c|c|c|c|c|}
\hline Name & Antibody & Linker & Cytotoxic payload & Cancers being studied in \\
\hline MEDI-42 (NCT02576548) & $\begin{array}{l}\text { MAb } 39 \mathrm{~S} \text { with Trastuzumab } \\
\text { scFv at } \mathrm{N} \text { terminus }\end{array}$ & $\begin{array}{l}\text { SC-Lys- } \\
\text { AZI3599I85 } \\
\text { Cleavable }\end{array}$ & $\begin{array}{l}\text { Tubulysin/ } \\
\text { tubulin }\end{array}$ & $\begin{array}{l}\text { Advanced breast and gastric } \\
\text { cancers }\end{array}$ \\
\hline ARX788 (NCT025 I2237) & $\begin{array}{l}\text { Anti-HER2 MAb incorporating } \\
\text { non-natural amino acids for } \\
\text { site-specific conjugation }\end{array}$ & $\begin{array}{l}\text { PEG4-AS-269 } \\
\text { Non-cleavable }\end{array}$ & $\begin{array}{l}\text { Auristatin/ } \\
\text { tubulin }\end{array}$ & Breast and gastric cancers. \\
\hline SYD985 (NCT022777I7) & Trastuzumab & $\begin{array}{l}\text { Val-Cit-PABC- } \\
\text { CM-seco-DUBA } \\
\text { Cleavable }\end{array}$ & Duocarmycin/DNA & $\begin{array}{l}\text { Advanced solid tumors of any } \\
\text { histology }\end{array}$ \\
\hline $\begin{array}{l}\text { DS-820la } \\
\text { (NCT02564900) }\end{array}$ & Trastuzumab & $\begin{array}{l}\text { Gly-Gly-Phe-Gly- } \\
\text { Dxd Cleavable }\end{array}$ & Exatecan/topoisomerase I & advanced solid tumors \\
\hline $\begin{array}{l}\text { ADCT-502 } \\
(\text { NCT03 I 25200) }\end{array}$ & Trastuzumab & $\begin{array}{l}\text { Val-Ala-PABC } \\
\text { Cleavable }\end{array}$ & $\begin{array}{l}\text { Pyrrolobenzodiazepine } \\
\text { (PBD) dimer/DNA }\end{array}$ & $\begin{array}{l}\text { HER2 + breast, NSCLC, } \\
\text { gastroEsophageal, bladder cancer }\end{array}$ \\
\hline $\begin{array}{l}\text { Glembatumumab vedotin } \\
\text { CDX-0I I CRO I I-vc- } \\
\text { MMAE (NCTOI997333) }\end{array}$ & $\begin{array}{l}\text { Glycoprotein non-metastatic b } \\
\text { (GPNMB) }\end{array}$ & $\begin{array}{l}\text { Val-Cit-PABC- } \\
\text { MMAE Cleavable }\end{array}$ & $\begin{array}{l}\text { Auristatin/ } \\
\text { tubulin }\end{array}$ & $\begin{array}{l}\text { Metastatic TNBC Expression of } \\
\text { GPNMB required } 9\end{array}$ \\
\hline \multicolumn{5}{|l|}{$* *$ Phase II } \\
\hline $\begin{array}{l}\text { SAR566658 anti-CA6- } \\
\text { DM4 (NCT02984683) } \\
\text { **Phase II }\end{array}$ & CA6 Sialoglycotope of MUC-I & $\begin{array}{l}\text { Sterically-stabilized } \\
\text { disulfide-DM4 } \\
\text { Cleavable }\end{array}$ & Maytansinoid/tubulin & $\begin{array}{l}\text { Measurable metastatic TNBC I-3 } \\
\text { prior chemotherapy regimens } \\
\text { CA6 expression required }\end{array}$ \\
\hline $\begin{array}{l}\text { PF-6647020 } \\
\text { (NCT02222922) }\end{array}$ & PTK7 & $\begin{array}{l}\text { Val-Cit-PABC- } \\
\text { auristatin0I0I } \\
\text { Cleavable }\end{array}$ & $\begin{array}{l}\text { Auristatin/ } \\
\text { tubulin }\end{array}$ & $\begin{array}{l}\text { advanced solid tumors Part 2: } \\
\text { includes TNBC with moderate to } \\
\text { high PTK7 expression }\end{array}$ \\
\hline $\begin{array}{l}\text { PF-6647263 } \\
\text { (NCT02078752) }\end{array}$ & Ephrin-A4 & $\begin{array}{l}\text { Hydrazone } \\
\text { calicheamicin } \\
\text { Cleavable }\end{array}$ & Enediyne/DNA & $\begin{array}{l}\text { Part I: advanced solid tumors Part } \\
\text { 2:TNBC }\end{array}$ \\
\hline $\begin{array}{l}\text { SAR428926 } \\
(\text { NCT0257578I) }\end{array}$ & LAMP-I & $\begin{array}{l}\text { Disulfide-DM4 } \\
\text { Cleavable }\end{array}$ & Maytansinoid/tubulin & $\begin{array}{l}\text { Advanced malignancies including } \\
\text { HER2 negative breast Expansion in } \\
\text { LAMP-I positive TNBC }\end{array}$ \\
\hline PCA062 (NCT02375958) & $\begin{array}{l}\text { P-Cadherin } \\
\text { Cadherin3 }\end{array}$ & $\begin{array}{l}\text { SMCC-DMI Non- } \\
\text { cleavable }\end{array}$ & Maytansinoid/tubulin & $\begin{array}{l}\text { Three cohorts including P-CAD } \\
\text { positive TNBC }\end{array}$ \\
\hline $\begin{array}{l}\text { SGN-LIVI } \\
\text { (NCT0I969643) }\end{array}$ & LIVI SLC39A6 & $\begin{array}{l}\text { Val-Cit-PABC- } \\
\text { MMAE Cleavable }\end{array}$ & $\begin{array}{l}\text { Auristatin/ } \\
\text { tubulin }\end{array}$ & $\begin{array}{l}\text { Locally advanced or metastatic } \\
\text { breast cancer positive for LIV-I } \\
\text { expression }\end{array}$ \\
\hline
\end{tabular}

Source: Clinicaltrials.gov.

The third phase III randomized study of T-DM1, TH3RESA, ${ }^{29}$ randomized 404 patients in a 2:1 ratio to either T-DM1 (404 patients) or treatment of physician's choice (TPC) (198 patients). The eligible patients had either metastatic or non-resectable locally advanced her2 positive disease and received both Lapatinib plus Capecitabine and a taxane. TPC was limited to chemotherapy (any single agent), hormonal therapy for hormone receptor (HR)-positive disease (singleagent or dual therapy), or HER2-directed therapy (single-agent, 
dual her 2-targeted therapy, or combination with either single-agent chemotherapy or single-agent hormonal treatment). Best supportive care alone was not allowed. The median number of $t$ was 4 (range from 1 to 19), excluding single agent endocrine treatment. The results of TH3RESA made T-DM1 as an appealing drug in the third line setting for those who progressed on a taxane plus Trastuzumab and Lapatinib plus Capecitabine based regimens. The PFS was 6.2 months Vs. 3.3 months with the control. This benefit was consistent across all subgroups studied. The six months and one-year survival rates were higher in the T-DM1 arm, but the OS was not significant statistically at first interim analysis. T-DM1, given its efficacy in her 2-positive breast cancer and its activity in preclinical models in Her-2 amplified gastric carcinoma, is a target worth studying in metastatic gastric cancer. Currently, a phase II/III study is enrolling patients in this setting.

\section{Sacituzumab govitecan (SG)}

SG is a newer ADC currently undergoing clinical trials for triple negative breast cancer (TNBC) in the metastatic setting. ${ }^{28} \mathrm{SG}$ consists of the cytotoxic payload of an active metabolite of irinotecan, SN38 (Govitecan), which links with a humanized IgG monoclonal antibody (Sacituzumab) targeted against TROP-2, a cell-surface glycoprotein identified in trophoblast cancer cell line. TROP-2 was chosen as the target as the ninety percent of triple negative breast cancer cells express this glycoprotein. Govitecan is 100 - to 1,000 fold potent than the parent compound, Irinotecan and contributes to its toxicity. The ADC aims to achieve higher levels of Govitecan by selectively delivering this drug to the target cancer cells. A phase I/ II study evaluated SG in heavily pretreated metastatic triple-negative breast cancer patients. Patients received $10-\mathrm{mg} / \mathrm{kg}$ dose level on days 1 and 8 of 21-day cycles. Prior therapies were Taxanes in 97\%, Cyclophosphamide in $91 \%$, Anthracyclines in $84 \%$, and Platinum agents in 70\%. As of August 2016, after a median follow-up of 16 months and after a median of 14 doses, seven remained on therapy out of 69 patients. 21 patients achieved ORR $(30 \%, 95 \% \mathrm{CI}=20 \%$ to $43 \%$ ).Nineteen patients showed partial response and two showed a complete response. Thirty patients achieved stable disease. Median duration of response was 8.9 months ( $95 \% \mathrm{CI}=6.1$ to 11.3 months), median PFS was 6.0 months ( $95 \% \mathrm{CI}=5.0$ to 7.3 months) and, median OS was 16.6 months $(95 \% \mathrm{CI}=11.1-20.6$ months). In 48 patients whose Trop 2 expression was measured by immunohistochemistry in archival tumors, $42(88 \%)$ had moderate $(2+)$ to strong (3+) Trop-2 staining. All responders had moderate to strong staining, and a trend towards PFS was seen in these patients compared to those with weak staining. Importantly, in this study, four patients were previously treated with anti-PDL1 antibody, with one achieving a response for four months. The investigators concluded noted, "This anecdotal observation suggests that the [antibody drug conjugate] and PD-1/ PD-L1 antibodies represent non-cross-resistant therapeutic options for a potential combination therapy, which requires further study." Grade 3 or 4 adverse events noted in the study were neutropenia $(39 \%)$, anemia (14\%), diarrhea (13\%), vomiting $(10 \%)$, and febrile neutropenia (7\%). ${ }^{30}$ In February 2016, SG has received a breakthrough therapy designation from FDA for the treatment of patients with heavily pretreated metastatic TNBC given its significant efficacy seen in preclinical trials. Currently ASCENT phase III trial is enrolling patients in the United States [NCT02574455].

\section{Conclusion}

ADCs offer enormous opportunities for developing targeted therapies in solid tumors as well as hematologic malignancies. The mechanism of these drugs improves the therapeutic window of the cytotoxic chemotherapy and reduces the systemic toxicity. ADCs have single-agent activity and have synergistic activity in combination with other active drugs such as monoclonal antibodies. Another exciting target for these drugs is the stroma of the tumor where they can be used to target tumor microenvironment which can interfere with angiogenesis, proliferation, invasion, and metastases. Another possibility is using them in combination with immunotherapies as ADCs can be designed to potentiate immune responses. ADCs opened the era of "personalized medicine," as conceptually, these should be active in any cancer cell expressing the antigen of interest in enough numbers and density, irrespective of tissue of origin. Although ADCs are promising as targeted therapy, they have some limitations. The large size of the antibodies inhibits penetration into the tumors. Given the advantage of long in vivo half-lives of antibodies, ongoing research to overcome this limitation is the development of conjugates to antibody fragments or delivery systems other than antibodies with smaller size with improved tumor penetrance.

\section{Acknowledgement}

None.

\section{Conflict of interest}

None.

\section{References}

1. Tandra P, Krishnamurthy J, Bhatt VR, et al. Autoimmune cytopenias in chronic lymphocytic leukemia, facts and myths. Mediterr J Hematol Infect Dis. 2013;5(1):e2013068.

2. Pham A, Chen R. Brentuximab vedotin for the treatment of Hodgkin's lymphoma. Expert Review of Hematology. 2015;8(4):403-412.

3. Chau I, Barton S. IS6-4: Anti-CD30 Antibody Drug Conjugate Therapy In Hodgkin Lymphoma And Cd30 Lymphoma. Annals of Oncology. 2013;24(suppl_9):9-18.

4. Younes A, Bartlett NL, Leonard JP, et al. Brentuximab vedotin (SGN-35) for relapsed CD30-positive lymphomas. $N$ Engl $J$ Med. 2010;363(19):1812-1821.

5. Younes A, Gopal AK, Smith SE, et al. Results of a pivotal phase II study of brentuximab vedotin for patients with relapsed or refractory Hodgkin's lymphoma. J Clin Oncol. 2012;30(18):2183-2189.

6. Chen R, Gopal AK, Smith SE, et al. Five-year survival data demonstrating durable responses from a pivotal phase 2 study of brentuximab vedotin in patients with relapsed or refractory Hodgkin lymphoma. Blood. 2015;126(23):2736.

7. Chen R, Palmer JM, Tsai NC, et al. Brentuximab vedotin is associated with improved progression-free survival after allogeneic transplantation for Hodgkin lymphoma. Biol Blood Marrow Transplant. 2014;20(11):1864-1868

8. La Casce AS, Bociek G, Sawas A, et al. Brentuximab vedotin plus bendamustine: a highly active salvage treatment regimen for patients with relapsed or refractory Hodgkin lymphoma. Blood. 2015;126(23):3982.

9. Schoder H, Gerecitano JF, Hamlin P, et al. FDG-PET adapted sequential therapy with brentuximab vedotin and augmented ICE followed by autologous stem cell transplant for relapsed and refractory Hodgkin lymphoma. Blood. 2013;122(21):2099.

10. Gopal AK, Ramchandren R, Connor OA, et al. Safety and efficacy of brentuximab vedotin for Hodgkin lymphoma recurring after allogeneic stem cell transplantation. Blood. 2012;120(3):560-568. 
11. Moskowitz $\mathrm{CH}$, Nademanee A, Masszi T, et al. Brentuximab vedotin as consolidation therapy after autologous stem-cell transplantation in patients with Hodgkin's lymphoma at risk of relapse or progression (AETHERA): a randomised, double-blind, placebo-controlled, phase 3 trial. Lancet. 2015;385(9980):1853-1862.

12. Connors JM, Jurczak W, Straus DJ, et al. Brentuximab Vedotin with Chemotherapy for Stage III or IV Hodgkin's Lymphoma. $N$ Engl J Med. 2018;378(9):878.

13. Bross PF, Beitz J, Chen G, et al. Approval summary: gemtuzumab ozogamicin in relapsed acute myeloid leukemia. Clin Cancer Res. 2001;7(6):1490-1496.

14. Sievers EL, Larson RA, Stadtmauer EA, et al. Efficacy and safety of gemtuzumab ozogamicin in patients with CD33-positive acute myeloid leukemia in first relapse. J Clin Oncol. 2001;19(13):3244-3254.

15. Larson RA, Sievers EL, Stadtmauer EA, et al. Final report of the efficacy and safety of gemtuzumab ozogamicin (Mylotarg) in patients with CD33-positive acute myeloid leukemia in first recurrence. Cancer. 2005;104(7):1442-1452.

16. Petersdorf SH, Kopecky KJ, Slovak M, et al. A phase 3 study of gemtuzumab ozogamicin during induction and postconsolidation therapy in younger patients with acute myeloid leukemia. Blood. 2013;121(24):4854-4860.

17. Appelbaum FR, Bernstein ID. Gemtuzumab ozogamicin for acute myeloid leukemia. Leukemia. 2017;31(9):1855-1868.

18. Castaigne S, Pautas C, Terre C, et al. Effect of gemtuzumab ozogamicin on survival of adult patients with de-novo acute myeloid leukaemia (ALFA-0701): a randomised, open-label, phase 3 study. Lancet. 2012;379(9825):1508-1516.

19. Hills RK, Castaigne S, Appelbaum FR, et al. Addition of gemtuzumab ozogamicin to induction chemotherapy in adult patients with acute myeloid leukaemia: a meta-analysis of individual patient data from randomised controlled trials. Lancet Oncol. 2014;15(9):986-996.

20. De Vries J, Zwaan CM, De Bie M, et al. The novel calicheamicinconjugated CD22 antibody inotuzumab ozogamicin (CMC-544) effectively kills primary pediatric acute lymphoblastic leukemia cells Leukemia. 2012;26(2):255-264.

21. Kantarjian HM, DeAngelo DJ, Stelljes M, et al. Inotuzumab ozogamicin versus standard therapy for acute lymphoblastic leukemia. N Engl J Med 2016;375(8):740-753.

22. Lambert JM, Berkenblit A. Antibody-Drug Conjugates for Cancer Treatment. Annu Rev Med. 2018;69:191-207.

23. Sehn LH, Herrera AF, Matasar MJ, et al. Addition of Polatuzumab Vedotin to Bendamustine and Rituximab (BR) Improves Outcomes in Transplant-Ineligible Patients with Relapsed/Refractory $(R / R)$ Diffuse Large B-Cell Lymphoma (DLBCL) Versus BR Alone: Results from a Randomized Phase 2 Study. Prospective Clinical Trials: Georgia World Congress Center, USA; 2017.

24. Girish S, Gupta M, Wang B, et al. Clinical pharmacology of trastuzumab emtansine (T-DM1): an antibody-drug conjugate in development for the treatment of HER2-positive cancer. Cancer Chemother Pharmacol. 2012;69(5):1229-1240.

25. Slamon DJ, Leyland-Jones B, Shak S, et al. Use of chemotherapy plus a monoclonal antibody against HER2 for metastatic breast cancer that overexpresses HER2. N Engl J Med. 2001;344(11):783-792.

26. Verma S, Miles D, Gianni L, et al. Trastuzumab Emtansine for HER2-Positive Advanced Breast Cancer. $N$ Engl $J$ Med. 2012;367(19):1783-1791.

27. Perez EA, Barrios C, Eiermann W, et al. Trastuzumab emtansine with or without pertuzumab versus trastuzumab plus taxane for human epidermal growth factor receptor 2-positive, advanced breast cancer: primary results from the phase III MARIANNE study. J Clin Oncol. 2017;35(2):141-148.

28. Starodub AN, Ocean AJ, Shah MA, et al. First-in-Human Trial of a Novel Anti-Trop-2 Antibody-SN-38 Conjugate, Sacituzumab Govitecan, for the Treatment of Diverse Metastatic Solid Tumors. Clin Cancer Res. 2015;21(17):3870-3878.

29. Krop IE, Kim SB, Gonzalez MA, et al. Trastuzumab emtansine versus treatment of physician's choice for pretreated HER2-positive advanced breast cancer (TH3RESA): a randomised, open-label, phase 3 trial. Lancet Oncol. 2017;18(6):743-754.

30. Bardia A, Mayer IA, Diamond JR, et al. Efficacy and safety of antiTrop-2 antibody drug conjugate sacituzumab govitecan (IMMU-132) in heavily pretreated patients with metastatic triple-negative breast cancer. J Clin Oncol. 2017;35(19):2141-2148. 